\title{
A Conspiração dos Trustes Ameaça o Desenvolvimento: política e imaginário nas páginas do jornal Última Hora durante o governo Kubitschek \\ (1955-1960) \\ Jefferson José Queler
}

Resumo: Imprensa, economia e política são termos comumente inseridos no domínio de uma suposta racionalidade pura. Mitos e paixões raramente são admitidos nessas áreas. Neste texto, sugiro como figuras imaginárias desempenharam um papel decisivo na política brasileira na década de 1950. Por meio das páginas do jornal Última Hora, é possível perceber que determinados grupos sociais mobilizaram o mito da conspiração, conforme definido por Raoul Girardet, para defender seu projeto de desenvolvimento e atacar a forma pela qual os investimentos estrangeiros aumentavam sua participação na economia nacional, especialmente durante a administração Kubitschek. Concluo que mitos e símbolos do imaginário podiam ser utilizados para apoiar a democracia e os programas políticos. Palavras-chave: Mito da Conspiração. Desenvolvimento. Governo Kubitschek. Jornal Última Hora.

\footnotetext{
* Pós-Doutor em História pela Unicamp e professor adjunto do Departamento de História da Universidade Federal de Ouro Preto. E-mail: jeffqueler@ hotmail.com.
} 
A Conspiração dos Trustes Ameaça o Desenvolvimento...

\begin{abstract}
"Hesitamos [...] em afirmar que o pensamento mítico tenha sido abolido [...] Ele conseguiu sobreviver, embora radicalmente modificado (se não perfeitamente camuflado)."
\end{abstract}

(ELIADE, 2002, p. 102)

\begin{abstract}
"O que Getúlio Vargas esclareceu, apontou e acusou, no documento que tomava a decisão trágica [...] está aí, diante de nós, espumejando ódio de novo, articulando atentados de novo, tentando entregas inconfessáveis de novo." (Coluna Flash do Momento, Última Hora, 19. 04. 1958)
\end{abstract}

\title{
Introdução
}

A crescente internacionalização da economia brasileira, ao longo da década de 1950, provocou temores e incertezas entre diversos grupos sociais, os quais temiam ser prejudicados pelo capital estrangeiro. Por isso, evocaram não apenas argumentos políticos e econômicos, mas também medos coletivos e figuras do imaginário como forma de imprimir outras direções à história. E a imprensa, supostamente imparcial e objetiva, foi veículo privilegiado para a difusão desse tipo de mensagem. Quais eram esses grupos? Algum projeto político dava-lhes certa coesão? De que meios eles se serviram para defender seus propósitos e aspirações? Tais são os principais problemas a serem discutidos com a análise da atuação política do jornal Última Hora $(\mathrm{UH})$ durante o governo Kubitschek (1955-1960). ${ }^{1}$

\section{Um projeto para o Brasil}

O jornal UH é muito conhecido na história da imprensa brasileira por suas estreitas ligações com o governo de Getúlio Vargas desde o início da década de 1950. Ao ser eleito presidente da República naquelas circunstâncias, ele percebeu que tinha a oposição da maioria dos grandes órgãos de imprensa. Com o intuito de ampliar a cobertura de seus atos e discursos, decidiu apoiar a fundação de um jornal. Para a tarefa, encarregou o jornalista Samuel Wainer, o qual fizera a cobertura de sua recente campanha presidencial para

Anos 90, Porto Alegre, v. 20, n. 37, p. 269-290, jul. 2013 
os Diários Associados. Wainer conseguiu recursos de grandes empresários e de instituições públicas, como o Banco do Brasil, para dar início à empresa. Fundou um jornal que procurou conquistar leitores notadamente entre os trabalhadores, com ênfase em reportagens policiais e esportivas, além de entretenimento em geral, sem perder o viés político em prol de Vargas (GOLDENSTEIN, 1987, p. 179-181).

À medida que se tornou uma rede de jornais espalhada pelo país e conquistou significativo número de leitores, a UH passou a ser violentamente atacada por políticos e órgãos de imprensa contrários ao presidente, principalmente por Carlos Lacerda. Em meio a esse processo, foi investigada por uma Comissão Parlamentar de Inquérito (CPI), sob a acusação de ter recebido empréstimos oficiais, episódio que contribuiu para acirrar a crise do governo, dramatizada pelo suicídio de Vargas, em 1954. Mesmo assim, a UH sobreviveu a esta e a outras numerosas polêmicas que abalaram sua condição de empresa, permanecendo ativa até meados de 1960, quando foi atingida pela ação dos militares no poder. Qual teria sido então o papel desempenhado pelo jornal no cenário político brasileiro após a morte do presidente que estivera tão visceralmente a ele ligado? Ainda que, na maioria dos casos, a UH tenha se colocado ao lado do governo Kubitschek, veiculou um projeto para o país distinto das diretrizes governamentais. Tal fato pode dar ensejo à investigação de suas relações e de seus laços com grupos sociais específicos.

Em suas memórias, Wainer apresenta sua versão do impacto que o suicídio de Vargas tivera sobre ele e seu jornal (WAINER, 1998, p. 206). Conta que foi conclamado por ruidosa massa popular a comentar o ocorrido em frente ao prédio da UH. Em sua exposição, pediu para que seus espectadores mantivessem a tranquilidade e continuassem a defender o legado varguista. E afirma: "Naquele momento, compreendi que a Última Hora sobreviveria ao homem que havia inspirado sua criação". Teria tido certeza disso naquelas circunstâncias, como demonstra mais de vinte anos depois, no início da década de 1980? De qualquer forma, mais do que a um homem, o jornal estava vinculado a um projeto político. É o que pode ser notado na coluna Flash do Momento, em 19 de abril de 1958, em comentários acerca das comemorações do aniversário do falecido presidente $^{2}$ :

Anos 90, Porto Alegre, v. 20, n. 37, p. 269-290, jul. 2013 


\section{A Conspiração dos Trustes Ameaça o Desenvolvimento...}

De suas ações e intervenções surgiu a indústria pesada, surgiu o monopólio estatal do petróleo, surgiu a política trabalhista. [...] Quando os problemas do trabalho eram meras questões policiais, policialmente solucionadas, Getúlio Vargas ajudou a levantar toda uma legislação de amparo aos que constituem a base do progresso nacional. Quando o País emergia da mais séria crise, conseqüência do colapso da Bolsa de Nova York, iniciou os empreendimentos fundamentais da industrialização. [...] Getúlio Vargas fundou o Brasil de hoje. (Última Hora, Flash do Momento, 19 abr. 1958, p.3)

No restante do texto, o leitor é chamado a defender essas orientações, supostamente ameaçadas pelo "entreguismo", isto é, todos aqueles interessados em desregulamentar a ação do governo e assim facilitar o domínio estrangeiro no país. Uma entidade maléfica será construída nas páginas da UH sob a clave do mito da conspiração. Algo que já podia ser entrevisto em documento de grande impacto e circulação, a Carta-Testamento de Vargas (Apud CARONE, 1980, p. 58-59), na qual este empregou imagens recorrentes no imaginário - composto tanto por um esquema de interpretação quanto de valorização, os quais suscitam a adesão dos indivíduos a um sistema de valores. (BACZKO, 1984, p. 35). No texto, aparece a imagem de uma campanha "subterrânea" de grupos internacionais para continuar "sugando" o povo brasileiro: elementos muito presentes anos depois nas opiniões políticas emitidas pelo jornal. Adalgisa Nery, por exemplo, em coluna de 19 de abril de 1960, data do aniversário do falecido presidente, atualiza os apelos míticos dele (p. 02): "A campanha subterrânea dos grupos internacionais auxiliados pelos nacionais, levou Getúlio Vargas à morte e permanece no firme propósito de levar o Brasil ao mesmo desespero".

O imaginário surge como recurso para a mobilização de medos e interesses coletivos, em nome de uma determinada orientação política. Segundo Raoul Girardet, apesar de os mitos apresentarem chaves de leitura comuns ao longo do tempo, sua produção é histórica (GIRARDET, 1987, p. 9-21). E tarefa do historiador, ou, poderíamos acrescentar, de quem os analisa, relacionar o seu aparecimento com tal ou qual "[...] fenômeno de ruptura ou de mutação, tal crise ou

Anos 90, Porto Alegre, v. 20, n. 37, p. 269-290, jul. 2013 
tal situação de ordem política, econômica ou social. Cabe-lhe igualmente pesquisar quais grupos ou quais meios foram seus focos privilegiados" (idem, p. 21). O mito da conspiração na UH foi elaborado num momento em que a economia brasileira era crescentemente internacionalizada, num mundo em que os territórios e fronteiras mostravam-se cada vez mais como obstáculos para o fluxo de mercadorias e de capitais (HOBSBAWM, 1996, p. 272). Resta avaliar quais grupos se sentiram ameaçados com esse processo e como eles atuaram na produção de mitos nas páginas do jornal.

As investigações de Maria Antonieta Leopoldi sobre as associações industriais naquele período ajudam-nos a projetar luzes sobre essa questão (LEOPOLDI, 2000, p. 135-136). Entre outros assuntos, ela analisa algumas propostas presentes em tais agremiações sobre os rumos da industrialização brasileira, desencadeadas por ocasião dos debates sobre a abertura de mercados ocorridos no contexto internacional do pós-Segunda Guerra Mundial. Nas reuniões para discutir formas de ampliação do comércio global, efetuadas no âmbito do então surgido GATT (General Agreement of Trade and Tariffs), o empresário industrial Euvaldo Lodi e seu assessor Rômulo de Almeida apontaram dificuldades impostas ao Brasil pelos países mais desenvolvidos na questão do acesso a seus mercados. Lodi destacava as preferências imperiais, o protecionismo agrícola, as tarifas proibitivas para produtos primários beneficiados e a concorrência do produto sintético. A partir destas constatações, passou a defender a orientação da produção agrícola e industrial para o mercado interno. Segundo Maria Antonieta Leopoldi, essas formulações surgiam paralelamente às teorias da Cepal (Comissão Econômica para a América Latina e o Caribe). Para ela, no que diz respeito à defesa do desenvolvimento para dentro: "Não foi [...] mera casualidade o fato de os discursos dos representantes industriais nos organismos corporativos adotarem, já em 1950, a terminologia cepalina" (idem, p. 136, grifos da autora).

A teoria cepalina foi então utilizada, entre outras coisas, como um instrumento nas mãos do empresariado nacional para atuar na luta política. A Cepal foi palco de estudos econômicos que definiram um aparato conceitual usado sob a forma de argumentos antiliberais a favor da industrialização dos países subdesenvolvidos 
(BIELSCHOWSKY, 1996, p. 13-29). Suas ideias, principalmente através da noção de centro-periferia, apresentavam o desenvolvimento econômico capitalista como um processo que tinha ocorrido de maneira diferenciada entre a América Latina e grande parte da Europa e da América do Norte, com o surgimento de países ricos e pobres. Nestes últimos, tinha-se formado uma economia de caráter dual, dividida entre o progresso e o atraso, o que nos termos cepalinos significava a presença de princípios de industrialização convivendo com a produção de gêneros agrícolas para a exportação. Este tipo de economia era marcado pela especialização e pela baixa produtividade da maioria de seus setores. E a prática de comércio entre países desenvolvidos e subdesenvolvidos resultava em perda de divisas para estes últimos, dado que a menor especialização de seus produtos lhes acarretava desvantagens nos termos de troca. Como solução, a teoria cepalina apontava para a realização de reformas estruturais como a industrialização planejada em alguns setores produtivos e a condução de uma reforma agrária: medidas destinadas a consolidar o capitalismo nos países latino-americanos. Nesse sentido, através do aumento da produção de produtos industrializados, visava-se a promover a substituição de itens importados como forma de equilibrar os balanços de pagamento e a diminuir a dependência externa desses países.

A teoria do crescimento para dentro foi retomada pelo empresariado nacional durante o governo Kubitschek. Segundo Maria Antonieta Leopoldi, isso ocorreu basicamente porque o tripé desenvolvimentista estruturado durante o governo Vargas foi alterado, isto é, o peso conferido ao Estado, indústrias locais e empresas estrangeiras na industrialização do país sofreu modificações (LEOPOLDI, 2000, p. 267). Os empresários industriais nacionais, que haviam recebido certa proteção sob o governo Vargas - através das políticas cambial e de crédito destinadas a regulamentar a entrada de investimentos estrangeiros no país - , passaram a conviver com uma presença mais acentuada do capital estrangeiro. Isso foi possível em função da instrução 113 da Superintendência da Moeda e do Crédito (SUMOC), que facilitou a importação de equipamentos sem cobertura cambial pelas empresas estrangeiras, o que concedeu grandes vantagens a estas últimas em relação a suas congêneres nacionais.

Anos 90, Porto Alegre, v. 20, n. 37, p. 269-290, jul. 2013 
Segundo Maria Antonieta Leopoldi, essa orientação fez com que muitos industriais locais se sentissem desprotegidos pelo Estado. Por isso, conduziram campanhas junto à imprensa e ao movimento estudantil como forma de divulgar seu "nacionalismo", e chegaram até mesmo a recorrer a uma aliança com o Partido Comunista, seu antigo inimigo (idem, 2000, p. 258). As posições políticas da $\mathrm{UH}$ revelam justamente um afinamento com as aspirações do empresariado nacional. Também não se deve desprezar os atrativos de seu projeto - em larga medida identificado com o programa do Partido Trabalhista Brasileiro (PTB) -, para parcela das camadas médias e para os trabalhadores, ciosos de medidas redistributivistas e de proteção social previstas e implementadas por essa diretriz política: sujeitos, portanto, e não simplesmente pessoas manipuladas, como queriam as diversas teorias sobre o "populismo" (FERREIRA, 2001, p. 7-17).

Tal projeto de desenvolvimento fica bem claro nas páginas do jornal. A produção e o comércio de café, por exemplo, foram vistos como uma plataforma para impulsionar a industrialização brasileira, como defende o colunista Paulo Silveira, em 7 de julho de 1959, por ocasião de seus comentários sobre evento ocorrido no Rotary Club de São Paulo3. Partindo do pressuposto de que o país exportaria dezoito milhões de sacas e continuaria a manter estoques do produto naquele ano, propõe a conquista de novos mercados no exterior, especialmente na Europa oriental. Queixa-se ainda do papel da Inglaterra e dos Estados Unidos como intermediários na venda do café brasileiro para países como Hungria e Bulgária, por auferirem lucros que deveriam ser do Brasil. E, em razão da dificuldade em se obter ganhos em moeda com os países do bloco socialista, sugere que, por meio de operações de troca: "podemos transformar os nossos estoques retidos em divisas e equipamentos originários dos países socialistas - pois é do café que teremos de partir para a transformação econômica do País, do subdesenvolvimento à industrialização.” (SILVEIRA, 7 jul. 1959, p. 3).

Ao mesmo tempo em que o campo era tomado como ponto de partida para a aceleração da industrialização, a estrutura agrária do país era vista como um empecilho para a concretização desse objetivo. É o que se observa na coluna de Adalgisa Nery, em 3 de setembro de 1958, em meio a elogios à campanha de membros da 


\section{A Conspiração dos Trustes Ameaça o Desenvolvimento...}

Frente Parlamentar Nacionalista, grupo interpartidário de tendência progressista, para as eleições legislativas de 1958. Em sua avaliação, o latifúndio retirava do trabalhador do campo os ganhos do autêntico produtor de riquezas, em favor da manutenção de "grupos feudais", e por isso clamava por uma reforma agrária: "Todos, e principalmente as elites políticas, sabem que não haverá nenhuma espécie de liberdade para o povo brasileiro, nem desenvolvimento industrial [...] sem dar ao trabalhador da terra o seu lugar importante na sociedade do país" (NERY, 3 set. 1958, p. 3). Apesar de a colunista servir-se de terminologia então em voga entre militantes comunistas, relacionada à suposta existência de uma estrutura feudal no Brasil, veremos que as propostas dela e do jornal nada tinham de revolucionárias. Elas estavam voltadas, isto sim, para o incremento do mercado interno e para a formação de um tipo específico de capitalismo.

Outra face do projeto da UH era o revigoramento do aparato protecionista da economia brasileira. As remessas de lucros ao exterior eram consideradas prejudiciais ao Brasil e por isso deveriam ser controladas. Tal é a opinião de Paulo Silveira, em 22 de julho de 1959, ao elogiar projeto de lei do deputado petebista Sérgio Magalhães destinado a disciplinar o fluxo de riquezas para fora do país (SILVEIRA, 22 jul. 1959, p. 3). Para o colunista, investimentos externos eram bem-vindos, desde que gerassem divisas por aqui e que de algum modo elas fossem retidas para impulsionar o processo de desenvolvimento. Em direção semelhante, na coluna Flash do Momento, de 13 de maio de 1958, maior proteção era requerida para a indústria nacional, especialmente contra os efeitos da instrução 113 da SUMOC, combatida por não permitir que "setores tradicionais da indústria brasileira" usufruíssem das mesmas vantagens dos investidores estrangeiros (Última Hora, Flash do Momento, 13 maio 1958, p. 3). É o que procura exemplificar com a "onda de repulsa" ligada ao caso da multinacional American Can, favorecida no mercado de vasilhames para derivados de petróleo através de garantias cambiais, em detrimento de empresas brasileiras.

O programa de industrialização advogado para o Brasil no jornal conferia, portanto, ênfase ao crescimento econômico e a certa redistribuição de riquezas dentro das fronteiras nacionais. A Coluna de Última Hora de 22 de janeiro de 1959 permite essa leitura (p. 03). Nela, emergem comentários acerca de matérias publicadas 
nas páginas do jornal a respeito do município de São Gonçalo, nas quais teria sido destacada a presença de pessoas que trabalhavam apenas pela alimentação e que nunca tinham deixado seu local de trabalho. Algo que contrastava com os centros urbanos mais desenvolvidos próximos dali: atestado da permanência de um "Brasil do século XIX" ou da coexistência do "atraso com progresso". Diante disso, o jornal posiciona-se: "Enquanto tais populações miseráveis não se converterem em mercado não poderemos dar os passos necessários à frente, permanecendo [...] limitados, onerados". Não se tratava apenas de inserir tais pessoas no mercado consumidor, como veremos, mas também de conferir-lhes um padrão de vida mais elevado ou minimamente digno.

O editorial publicado em 25 de maio de 1959 esclarece bem tal orientação, ao sustentar que a tese do desenvolvimento industrial, ligada "à modernização da agricultura e ao enriquecimento do mercado interno, ganha forças [...] criando uma mentalidade, segundo a qual [...] patrões e empregados devem caminhar irmanados" (Editorial, 25 maio 1959, p. 5). É apenas sob essa condição, a da harmonização entre capital e trabalho, que o jornal apoiava a realização de greves e a legislação trabalhista. Dessa forma, ainda que seja duvidoso afirmar que tais princípios e práticas fossem capazes de eliminar os conflitos sociais, fica bem claro que eles ofereciam atrativos para mais de um dos grupos em que se dividia a sociedade brasileira, entre eles, empresários, camadas médias e trabalhadores. Em editorial de 8 de fevereiro de 1958, enfim, tal projeto de desenvolvimento é bem sintetizado e contrastado com o que não se queria (capa):

Trata-se de realizar o desenvolvimento que resulte em verdadeiro proveito para a maioria dos brasileiros, que corresponda a um aumento do poder de compra e dos níveis de lucro, que traga salários melhores e portanto, padrão de vida mais humano, quando o trabalhador poderá consumir algo mais do que o mínimo que lhe assegura subsistência. Não há desenvolvimento, pois, sem uma orientação nacionalista. Muito ao contrário, as obras e as empresas mais avançadas, de técnica moderna e de amplitude apreciável, podem tornar-se fatores de retardo entre nós, se não montadas de acordo com as necessidades nacionais e deixando no mercado interno os frutos do esforço de que resultam (Editorial, 8 fev. 1958, capa). 
$\mathrm{Na}$ opinião do jornal, a industrialização criara até mesmo as condições para que os habitantes do território brasileiro se constituíssem como povo. Na coluna Flash do Momento, em 17 de abril de 1958, há o diagnóstico de que lutar pelo desenvolvimento do país havia se tornado mais fácil devido à emergência daquele novo protagonista. ( (Última Hora, Flash do Momento, 17 abr. 1958, p. 03). Com o advento da indústria pesada, a abertura de mercados à indústria de bens de consumo e a ampliação do mercado interno, teria havido um "correspondente esclarecimento das massas e das elites", transformados em sustentáculos do regime democrático: forma de governo que não estaria de todo assegurada, visto que inimigos do referido projeto de desenvolvimento eram tratados pelo jornal como antidemocratas e golpistas. É que pode ser notado em editorial publicado em 16 de novembro de 1959, em que emergem críticas ao ex-chanceler João Neves da Fontoura, por esse ter manifestado contrariedade aos princípios defendidos pela UH (capa). Nele, há críticas em relação à dependência da economia brasileira do café em anos anteriores e o elogio às transformações subsequentemente operadas, com a elevação do Brasil à condição de maior país industrial da América Latina. Diante disso, o editorial afirma ser natural a polarização das forças políticas: “[...] o das que querem impulsionar a marcha para a emancipação e o das que se empenham em deter essa marcha a qualquer preço". Quem formaria o segundo grupo? De que meios tais pessoas se serviam para realizar seus planos?

\section{A ameaça da conspiração}

No sétimo aniversário do jornal, em 12 de junho de 1957, Samuel Wainer assinou editorial em que proclamava serem as altas tiragens do periódico e suas receitas obtidas com publicidade "condição de completa independência com relação a interesses privados de grupos políticos, econômico financeiros ou sociais" (WAINER, 12 jun. 1957, p. 03). Tal retórica certamente era inspirada no princípio iluminista de compromisso com a verdade e com a objetividade, a "missão de imprensa". Nossa análise, por outro lado, sugere que a UH mantinha vínculos com grupos sociais, por mais velados que 
fossem. Ademais, para defender seu projeto de industrialização, o jornal serviu-se não apenas de argumentos econômicos ou políticos racionalmente construídos, como também do imaginário e da mobilização de medos coletivos, especialmente do mito da conspiração. Seus adversários e inimigos, ao advogarem maior abertura da economia brasileira para a penetração de capitais estrangeiros, foram enquadrados na representação de uma organização todo-poderosa agindo às escuras para dominar o país e abocanhar as suas riquezas.

É claro que havia matizes entre os grupos combatidos pela UH. Ricardo Bielschowsky agrupa as tendências teóricas e políticas em confronto no período de um modo que nos auxilia a compreender com quem o jornal travava seus diálogos e embates (BIELSCHOWSKY, 1996, p. 33-38). Em sua terminologia, a corrente neoliberal defendia a prioridade da livre movimentação das forças de mercado para estimular o crescimento da economia. Era formada por economistas como Octávio Gouveia de Bulhões, Denio Nogueira e Alexandre Kafka, que reconheciam o peso e a irreversibilidade da industrialização no país, mas concebiam a manutenção da estabilidade monetária como algo importante e criticavam as intervenções governamentais para estimular o crescimento da indústria. Outra tendência era formada por economistas como Eugênio Gudin e Daniel de Carvalho, que endossavam o princípio clássico da divisão internacional do trabalho em que o Brasil figuraria como exportador de gêneros agrícolas. E podemos imaginar o quanto tais posições agradavam aos cafeicultores. Estes, durante o governo Kubitschek, ao converterem suas receitas obtidas em moeda estrangeira com suas vendas no exterior, recebiam um valor menor do que o praticado em outras operações cambiais. Assim, parte de seus lucros era direcionada para incentivar o programa de industrialização. O descontentamento dos cafeicultores chegou a tal ponto que, em 1957, chegaram a planejar uma "Marcha da Produção" rumo ao Palácio do Catete para pressionar o presidente a reformar o câmbio ${ }^{4}$.

Outro alvo da oposição da UH podia ser notado no que Ricardo Bielschowsky denomina corrente desenvolvimentista não nacionalista do setor público (idem, p. 105). Esta, com grande influência sobre as diretrizes governamentais e o Plano de Metas, era composta por 
figuras como Horácio Lafer, Valentin Bouças, Ary Torres, Glycon de Paiva, Lucas Lopes e Roberto Campos. Tal grupo convergia com os apoiadores da livre penetração de capital estrangeiro na economia brasileira e da estabilidade monetária; mas divergia deles na questão da industrialização planejada, da qual eram entusiastas. Cabe ressaltar que posições como essas eram compartilhadas com parcela do empresariado durante a administração Kubitschek, com destaque para os membros da Federação das Indústrias do Estado de São Paulo (FIESP), a qual contrapunha seu "nacionalismo sadio" ao "nacionalismo exacerbado”, tal qual expresso na UH (TREVISAN, 1986, p. 57).

A ação desses grupos, longe de constituir mera fantasia, foi bem real e se enraizou no aparelho estatal, na imprensa e em diversas outras esferas da sociedade brasileira, conforme demonstra pesquisa minuciosa de René Armand Dreifuss (DREIFUSS, 1981, p. 72-73). Este destaca que empresas transnacionais garantiram sua influência junto ao governo e à sociedade não apenas com pressões econômicas, como também com o apoio a pessoas vinculadas a seus interesses atuantes na administração pública. Para ele, esses grupos trabalharam no sentido de constituir "[...] um bloco econômico burguês modernizante-conservador, o qual se opôs à estrutura econômica oligárquico-industrial e ao regime político populista". Ao conceber tal unidade de ação e interesses, contudo, Dreifuss resvala no mito da conspiração, ao incorporar a ideia de sua existência. Algo tão presente nos debates políticos do período por ele estudado.

Segundo Girardet, a mitologia da conspiração ou do complô pode ser identificada em diferentes tempos e lugares - já aplicada a judeus, maçons e comunistas, para ficarmos apenas em alguns exemplos -, evidentemente com sentidos e objetivos diferentes em cada um dos casos (GIRARDET, 1987, p. 49). Suas chaves de leitura são bem conhecidas. Trata-se de uma organização que pretende expandir seu domínio em escala mundial. Em sua estrutura, uma liderança implacável e invisível sobrepõe-se a uma massa de cúmplices despidos de individualidade ou personalidade, simples engrenagens de uma máquina. Para atingir seus objetivos, atua em segredo e aplica todos os meios ao seu alcance tais como espionagem, suborno e delação. Infiltra-se assim no sistema educacional, na imprensa, nos mecanismos econômicos, para condicionar os 
espíritos da sociedade que pretende dominar. Em todas essas instâncias, os fios da manipulação encontram-se atados à organização, preparada para tomar posse das riquezas públicas (idem, p. 34-41). Entre seus membros, encontram-se personagens que se pautam por suas próprias leis e regras, uma vez que desprezam as instituições da sociedade que os abriga. Não causa espanto, assim, que o estrangeiro seja matéria-prima constante na confecção desse tipo de narrativa.

Os integrantes da organização agiriam nas sombras, no subterrâneo, a partir de onde se espraiariam para a sociedade em geral, tal qual uma infecção, um veneno, uma sujeira; tais quais animais repulsivos como serpentes, ratos, sanguessugas, polvos. São representados por meio de uma boca monstruosa, pronta para se agarrar às fontes da vida e delas sugar sangue até não poder mais (idem, p. 41-46). Tais imagens delineiam o que seriam as forças maléficas em oposição ao que se imagina ser o verdadeiro, o justo, o santo. Segundo Girardet, o mito da conspiração tende a aflorar num ambiente social e psicológico de incerteza, temor e angústia. Esta narrativa, no final das contas, assume uma função explicativa: a de reduzir todos os fatos a uma mesma lógica, a uma todo-poderosa causalidade, com o que procura conferir uma aparência racional e coerente na ordenação das coisas (idem, p. 47-55).

Ao que parece, a crescente penetração de conglomerados multinacionais no Brasil durante a década de 1950 era uma das grandes fontes de medo e incerteza para a configuração do mito do complô na UH. É o que transparece nas colocações de Adalgisa Nery, em 31 de dezembro de 1959, ao denunciar a ação dos trustes nos países subdesenvolvidos (NERY, 31 dez. 1959, p. 03). Ela assevera que, na lógica dessas organizações, havia o propósito de conduzir uma "guerra de extermínio" junto aos produtores independentes que se recusassem a se submeter a seus desígnios. Entre os métodos empregados pelos trustes, aponta-se a venda de seus produtos momentaneamente com prejuízo, com o fito de esmagar os rivais; o suborno dos diretores e empregados das empresas concorrentes; a corrupção dos funcionários das companhias de serviços públicos (em áreas de comunicação e transporte como ferrovias, correios, telégrafos), para obter informações privilegiadas 
sobre a concorrência. E, conforme a análise anterior, é possível supor que a perda de mercados e posição social para os conglomerados internacionais, independentemente dos meios utilizados por estes últimos, representasse uma ameaça concreta aos interesses de segmentos do empresariado, das camadas médias e dos trabalhadores. A questão central é identificar os momentos em que os temores suscitados por essa situação são transpostos para uma narrativa mítica, certamente para serem combatidos com mais eficácia por tais grupos na arena política.

A própria Adalgisa Nery fornece-nos pistas desse processo, ao criticar argumentos da oposição sobre as causas dos problemas brasileiros. Em sua coluna, de 10 de dezembro de 1959, ela rebate as acusações de que as ações do presidente ou as obras para a construção de Brasília eram os responsáveis pelo aumento da inflação e por desequilíbrios econômicos (NERY, 10 dez. 1959, p. 02). Em sua opinião, as reclamações aos dirigentes eram lícitas desde que orientadas para "a fonte geradora dos gravíssimos problemas nacionais"; algo que sugere o enquadramento dos fatos numa mesma lógica, traço fundamental do mito da conspiração. E arremata sua exposição com a caracterização dos "monopólios" como agentes onipresentes e onipotentes no contexto mundial. Afinal, são eles que "inspiram, traçam e fomentam as tensões internacionais", "plantam deliberadamente as sementes do ódio e da intriga entre nações entre nações e irmãos do mesmo solo", "disseminam em todos os países a arte de uma política que consiste em espremer ao máximo o contribuinte sem provocar nele a indignação do eleitor", e, por fim, elegem "o Presidente da República dos países de economia dominada".

Segundo Adalgisa Nery, em 12 de fevereiro de 1960, desde que os brasileiros amanhecem e escovam os dentes, até a última lâmpada que apagam, na madrugada, "[...] tudo, sem escapar um só produto, um só meio, um só objeto, pertence a empresas ianques" (NERY, 12 fev. 1960, p. 02). Estamos não apenas no reino das hipérboles, como também na esfera do mito: “Todos os lucros vão para o estrangeiro, todas as nossas matérias-primas são avaliadas e tomam o preço que a economia ianque impõe. Toda a nossa indústria [...] é esmagada". Em 8 de abril de 1960, ao comentar 
discurso de posse de Emílio Lang Jr. na Associação Comercial de São Paulo, no qual este teria declarado que capitalismo e liberdade eram indissociáveis, Adalgisa Nery evoca a imagem de uma marionete para representar o Brasil, tendo em vista o que seria a onipotência dos monopólios internacionais (NERY, 08 abr. 1960, p. 02): "Dizer, no Brasil, país cada dia mais pressionado pela fome e a miséria dirigida pelos cordões do capitalismo estrangeiro, que o capitalismo e liberdade são inseparáveis." era, na verdade, tratar de coisas totalmente opostas. Uma grande entidade maléfica toma forma nas posições políticas do jornal, considerada fonte última de nossas mazelas e infortúnios.

E eis que a célebre imagem da organização aparece na Coluna de Última Hora, em 13 de dezembro de 1958, em ocasião em que o jornal procura traçar as forças políticas em confronto no Brasil:

[...] há mil e um indícios de que existe perfeita e operativa organização, cujo trabalho vem sendo desenvolvido com rigoroso método, destinada a ajudar o desespero a tornarse mais desesperado, a esperança mais desesperançada [...] Esta organização é a mesma que montou [...] aquele dispositivo perfeitamente ajustado que falhou em 11 de novembro $^{5}$, no momento preciso, quando o Exército pôs fim às suas atividades, definindo o regime democrático como a base da existência de nosso povo. Todos os dias, aquela organização leva um grão de veneno ao povo, apontando os erros, a dissídia, a inoperância do Governo, o egoísmo e a versatilidade do Legislativo, os desmandos e as falhas da burocracia, os pequenos escândalos, os pequenos furtos, os pequenos males que nos atribulam. Prefere aquela organização conspirativa que tudo acabe pelo pior e que uma ditadurazinha traga aquilo por que tanto se bateu" (Última Hora, 13 dez. 1958, p. 03).

Qual organização, se não o complô, procura transmitir seu "veneno" à sociedade como forma de minar suas instituições democráticas? Mas e seus vínculos com interesses estrangeiros? Eles são sugeridos por Paulo Silveira em 15 de julho de 1959, em alerta sobre a suposta penetração da conspiração no seio do Exército para a 
eliminação dos pontos de vista "nacionalistas" (p. 03). Tais elementos, além da caserna, "Expandem-se pelas colunas pagas da imprensa 'soi-disant' conservadora, infiltram-se entre as entidades representativas das classes produtoras, procuram influenciar os moços das escolas e universidades". Afinal, o objetivo do "entreguismo reacionário", segundo a coluna Flash do Momento de 27 de setembro de 1958, era que o Brasil produzisse "[...] o máximo de produtos primários, que nos industrializemos o mínimo, e que esse mínimo seja estrangeiro, porque ao estrangeiro é que ele está ligado" (Última Hora, Flash do Momento, 27 set. 1958, p. 03).

Conspiração dos trustes e não dos comunistas, como queriam opositores das posições políticas do jornal. Adalgisa Nery, em 13 de outubro de 1959, disparou críticas contra o Coronel Humberto de Mello, secretário do Conselho de Segurança Nacional, em razão de este ter apontado a existência de uma "infiltração comunista" no Brasil (NERY, 13 out. 1959, p. 02). Como seria de se esperar, ela prontificou-se a inverter a equação e sustentou que a invasão ocorria, isto sim, através dos monopólios internacionais. Manifestando indignação com a fala do militar, coloca que "[...] além de pouco torna-se até afrontoso ao povo, reduzir todos os dramas brasileiros agora corporificados na fome, a uma infiltração comunista"; sinal de que seu adversário, ao reduzir todos os fatos a uma mesma lógica, empregava a mesma chave de leitura do mito por ela repetidamente utilizada? Provavelmente. Em 21 de agosto de 1959, Adalgisa Nery defende que a generalização da fome e da inquietação social estava relacionada à ação dos trustes, como se preparassem suas bocarras para se alojar no país (p. 02 tablóide): o "[...] leitor não sabe que os trustes internacionais dominam a economia do País, destroem a indústria nacional, aniquilam a produção, rebaixam o poder aquisitivo do indivíduo, sugam todas as vitalidades da Nação [...]?". O Partido Comunista do Brasil (PCB), na verdade, encontrava-se então na ilegalidade desde 1947, tendo sido considerado pelo Tribunal Superior Eleitoral (TSE) como instrumento de intervenção soviética no país (RODRIGUES, 1996, p. 412). Evidentemente, muitos de seus militantes continuaram atuando clandestinamente na década de 1950, e logo foram enquadrados por opositores seus na narrativa da conspiração. 
Para esta análise, importa destacar que projetos como os da UH também foram enquadrados no mito do complô, formado supostamente por comunistas. Basta lembrar o fato amplamente conhecido de que o governo do petebista João Goulart foi derrubado por aliança de civis e militares sob a justificativa de que conduzia o Brasil rumo ao comunismo: evidência de que tais diretrizes também despertavam temores e incertezas em determinados segmentos da sociedade brasileira. Verdadeiro confronto de imaginários ou mitologias políticas. Era crucial para o jornal, pois, dissociar suas orientações daquela doutrina política. Na coluna Flash do Momento de primeiro de abril de 1958, por exemplo, a decisão de Luís Carlos Prestes, conhecida liderança comunista, de voltar a aparecer em público após ter vivido clandestinamente por vários anos, parece ter provocado a associação entre as causas defendidas pela UH e o comunismo (p. 03). Segundo o jornal, o "entreguismo desorientado" levantava "velhas e rotas bandeiras, hoje totalmente desacreditadas", ao indicar que "[...] ser nacionalista é confundir-se com o comunismo e realizar os seus propósitos, e que o aparecimento do Sr. Prestes significa que o nacionalismo se confunde com comunismo".

$\mathrm{Na}$ opinião de Adalgisa Nery, em coluna de 3 de fevereiro de 1959, a retórica contra o comunismo deixava os flancos da administração pública abertos para a penetração dos trustes (p. 02, tablóide): "O nosso governo fala em excesso no combate ao comunismo, e com mais excesso de ignorância, empenha-se em combater a ideologia soviética"; ao mesmo tempo em que "permite dentro do governo o livre trânsito dos entreguistas, distribuindo-os oficialmente nos mais altos postos". Com isso, atacava diretamente figuras de proa do governo Kubitschek como o assessor de política exterior do presidente, Augusto Frederico Schmidt, o Ministro da Fazenda, Lucas Lopes, e o presidente do Banco Nacional de Desenvolvimento Econômico (BNDE), Roberto Campos, em razão de eles defenderem o aumento da penetração de capitais estrangeiros no Brasil. A colunista, em 19 de fevereiro de 1959, ao comentar manifestações estudantis contrárias à atuação de Roberto Campos na administração pública, ademais, traz à tona célebre imagem da mítica organização como a despersonalização daqueles que a integrariam, tidos como meras engrenagens de uma máquina (p. 02 tablóide):

Anos 90, Porto Alegre, v. 20, n. 37, p. 269-290, jul. 2013 
A máquina entreguista-negocista está maravilhosamente bem montada. Há também um grande estoque de peças para substituições imediatistas em caso de qualquer dificuldade no funcionamento da mesma. Roberto Campos é uma peça que pode ser substituída sem a menor interrupção da meta entreguista [...] O entreguismo encontra correspondência e garantia no aventureirismo, e desmontar essa poderosa máquina [...] torna-se quase impossível. De mais de um deles sabemos que tem feito uma carreira gloriosa, transformando-se em complemento imprescindível a essa engrenagem de desmoralização nacional.

Não que grupos interessados em derrubar o governo Kubitschek não existissem e não articulassem planos para tanto, fique bem claro (BENEVIDES, 1979, p. 162). Lembremos da revolta de Jacareacanga, em 1956, na qual oficiais ligados à Aeronáutica levantaram-se contra as autoridades federais. Em 1959, de forma semelhante, o tenente-coronel aviador Haroldo Veloso e vários outros militares e civis rebelaram-se e partiram para Aragarças-GO, de onde, sob a justificativa de que o governo era corrupto e comprometido com o comunismo internacional, pretendiam lançar uma operação para alijá-lo do poder. Ambas as revoltas terminaram sem atingir seus objetivos. De qualquer modo, foram ocasiões em que a ameaça da conspiração veio a público como uma ameaça concreta. Algo que podia ser elencado para indicar não serem as recorrentes invocações ao mito meras fantasias ou delírios. No editorial da UH de 12 de dezembro de 1959, por exemplo, há denúncias de que jornais oposicionistas queriam jogar uma "pá-de-cal" sobre o episódio de Aragarças, legando-o ao esquecimento (capa); ao passo que, para o jornal, "[...] a conspiração existiu e existe. As ligações com elementos civis são hoje do conhecimento amplo das Forças Armadas". Um indício de que dificilmente um mito se enraíza ou ganha credibilidade numa sociedade sem beber em algum aspecto de sua realidade, por mais que ele o distorça. 


\section{Considerações finais}

O afluxo de investimentos estrangeiros para o Brasil, como é amplamente sabido, foi facilitado pelo golpe de 1964. Repressão política, economia mais internacionalizada e modelo concentrador de renda foram características dos anos que se seguiram a esse fatídico episódio. Evidentemente, tal rumo não estava pré-determinado ao longo da década de 1950, tampouco era a mencionada ruptura institucional um desfecho inevitável. Evitemos as análises teleológicas. Grupos sociais e projetos políticos colocaram-se contra a crescente internacionalização da economia brasileira ao longo daquele período. Uma fração da burguesia industrial, setores das camadas médias e dos trabalhadores preferiram um modelo de desenvolvimento mais voltado para a ampliação do mercado interno do país, com certa redistribuição de renda. Em suma, apoiavam a constituição de um capitalismo menos plutocrático e mais protegido pelas fronteiras nacionais.

Em meio à luta política, que pudemos entrever através das páginas da $\mathrm{UH}$, tais grupos empregaram os mais diversos argumentos de caráter político e econômico, sem esquecer que atuaram no Congresso, nos sindicatos e nos movimentos sociais, para defender seus pontos de vista. Além de apelos racionais, mobilizaram medos e figuras imaginárias, com destaque para o mito da conspiração. Ao longo do governo Kubitschek, quando se acelera a penetração de capitais estrangeiros ou das empresas multinacionais, suas aspirações e seus temores parecem ter contribuído para forjar a representação de uma organização todo-poderosa agindo ocultamente para drenar as riquezas do país. Com este recurso, empenharam-se em imprimir um rumo alternativo à história do Brasil, e conquistas momentâneas foram obtidas. A vitória do trabalhismo com a ascensão de João Goulart à presidência, em 1961, porém, logo seria ofuscada pelo triunfo das forças de oposição, amplamente escoradas na ideia de que um complô comunista se apossava do governo. Dessa vez, o imaginário era instrumentalizado para liquidar o regime democrático; ao invés de revestir programas partidários de encanto e paixão, como chamarizes para a discussão de seus conteúdos: uma potencialidade das mitologias políticas. 


\section{'THE TRUSTS' CONSPIRACY THREATENS THE DEVELOPMENT: POLITICS AND IMAGINARY ON THE PAGES OF THE DAILY NEWSPAPER ÚLTIMA HORA (1955-1960)}

Abstract: Press, economy and politics are terms commonly inserted in the realm of an alleged pure rationality. Myths and passions are rarely admitted in such areas. In this text I suggest that imaginary figures played a decisive role in Brazilian politics during the 1950s. Through the pages of the daily newspaper Última Hora, it is possible to notice that certain social groups mobilized the conspiracy mith, as defined by Raoul Girardet, to defend their project of development and attack the way foreign investments were increasing their participation in the national economy, especially during Kubitschek administration. As a conclusion, I point out that miths and imaginary symbols could be used to support democracy and political programs.

Keywords: Conspiracy mith. Development. Kubitschek government. Daily newspaper Última Hora.

\section{Notas}

${ }^{1} \mathrm{O}$ acervo da UH encontra-se microfilmado no Arquivo do Estado de São Paulo. As posições políticas do jornal serão acompanhadas nos editorais e nas opiniões dos colunistas. Em entrevista concedida a Maria Aparecida de Aquino, um ex-colaborador do jornal, Jorge da Cunha Lima, declarou que o editorial era resultado da soma dos artigos dos grandes colaboradores (AQUINO, 1997, p. 15-24). Uma das principais colunistas do jornal, Adalgisa Nery, nasceu no Rio de Janeiro, em 1905. Após casar-se com o pintor Ismael Nery, travou contato com círculos intelectuais de destaque; nomes como os de Mário Pedrosa, Murilo Mendes, Aníbal Machado, Jorge de Lima, Antônio Bento e Manuel Bandeira. Com a morte do marido, passou a compor obras poéticas e literárias e a escrever para jornais e revistas. Casou-se novamente, desta vez com Lourival Fontes, ex-administrador do Departamento de Imprensa e Propaganda (DIP). Outro colunista, Paulo Silveira, nasceu em Aracaju, em 1919. Iniciou sua carreira jornalística no Rio de Janeiro, como repórter do jornal A Notícia. Na década de 1950, começou a trabalhar na UH, instituição em que chegaria a ocupar os cargos de secretário de redação e de diretor responsável.

${ }^{2}$ A pesquisa é parte de minha dissertação de mestrado, orientada pela Prof ${ }^{a}$. Dra. Vavy Pacheco Borges e financiada pelo CNPq. QUELER, Jefferson J. Democracia e desenvolvimento: os posicionamentos políticos do jornal Última Hora durante o governo Kubitschek (1957-1960). Campinas: IFCH/Unicamp, 2004.

Anos 90, Porto Alegre, v. 20, n. 37, p. 269-290, jul. 2013 
${ }^{3}$ Notamos certa uniformidade nas opiniões políticas emitidas no jornal entre os editoriais e colunistas. Isso explica-se, provavelmente, não apenas por afinidades ideológicas como também pelo crivo de Samuel Wainer. Moacir Werneck de Castro, ex-colaborador da UH, fornece as pistas: "Ele [Wainer] controlava os colunistas mais radicais, sempre tratando de manter com eles boas relações de camaradagem. Usava sua poderosa capacidade de persuasão junto a esses colaboradores e às vezes conseguia amansá-los." (CASTRO, 1993, p. 83-84).

${ }^{4}$ Mais informações sobre o governo Kubitschek podem ser obtidas no Dicionário Histórico-Biográfico-CPDOC-FGV.

${ }^{5}$ Logo após ter sido eleito presidente, em 1955, Juscelino Kubitschek teve a legitimidade de sua vitória contestada, notadamente por integrantes da União Democrática Nacional (UDN), por não ter conseguido mais de cinquenta por cento dos votos no pleito, a chamada maioria absoluta. Defensores desta posição, junto de setores das Forças Armadas, planejavam então estabelecer um "regime de exceção", tido como necessário para conduzir outra disputa eleitoral calcada em tal princípio. Diante disso, o General Henrique Teixeira Lott articulou grupos militares favoráveis à posse de Kubitschek e liderou um "contragolpe preventivo", atuando para garantir a subida deste último ao cargo.

\section{Referências}

AQUINO, Maria Aparecida de. Última Hora: batalhas perdidas, vitória na guerra!. In: Arquivo em imagens (série Última Hora). São Paulo: Arquivo do Estado de São Paulo, 1997.

BACZKO, Bronislaw. Les imaginaires sociaux: memoirs et espoirs collectifs. Paris: Payot, 1984.

BENEVIDES, Maria Victoria de Mesquita. O governo Kubitschek: desenvolvimento econômico e estabilidade política. Rio de Janeiro: Paz e Terra, 1979.

BIELSCHOWSKY, Ricardo. Pensamento econômico brasileiro: o ciclo ideológico do desenvolvimentismo (1930-64). Rio de Janeiro: Contraponto, 1996.

CARONE, Edgar. A Quarta República: 1945-1964 (documentos). São Paulo; Rio de Janeiro: Difel, 1980.

CASTRO, Moacir Werneck de. Samuel e Lacerda ficaram fascinados um pelo outro. In: CAMPOS, Anderson (Org.). A Última Hora de Samuel: nos tempos de Wainer. Rio de Janeiro: Ed. Grafitto, 1993.

DREIFUSS, René Armand. 1964 - A conquista do Estado. Ação política, poder e golpe de classe. Petrópolis: Vozes, 1981.

Anos 90, Porto Alegre, v. 20, n. 37, p. 269-290, jul. 2013 


\section{A Conspiração dos Trustes Ameaça o Desenvolvimento...}

ELIADE, Mircea. Mito e realidade. São Paulo: Ed. Perspectiva, 2002.

FERREIRA, Jorge (Org.). O populismo e sua história. Rio de Janeiro: Ed. Civilização Brasileira, 2001.

GIRARDET, Raoul. Mitos e mitologias politicas. São Paulo: Companhia das Letras, 1987.

GOLDENSTEIN, Gisela Taschner. Do jornalismo político à indústria cultural. São Paulo: Summus, 1987.

HOBSBAWM, Eric. Era dos extremos (1914-1991). São Paulo: Companhia das Letras, 1996.

LEOPOLDI, Maria Antonieta P. Política e interesses na industrialização Brasileira: as associações industriais, a política econômica e o Estado. Rio de Janeiro: Paz e Terra, 2000.

RODRIGUES, Leôncio Martins. O PCB: os dirigentes e sua organização. In: FAUSTO, Boris (Org.). História geral da civilização brasileira. O Brasil republicano III. Rio de Janeiro: Bertrand Brasil, 1996.

TREVISAN, Maria José. 50 anos em 5. Petrópolis: Ed. Vozes, 1986.

WAINER, Samuel. Minha razão de viver. Rio de Janeiro: Record, 1988.

Recebido em: 23/12/2011

Aprovado em: 20/12/2012 